\title{
The relationship between basal and acute HPA axis activity and aggressive behavior in adults
}

\author{
Robina Böhnke • Katja Bertsch • Menno R. Kruk • \\ Ewald Naumann
}

Received: 27 October 2009/Accepted: 7 March 2010/Published online: 24 March 2010

(C) The Author(s) 2010. This article is published with open access at Springerlink.com

\begin{abstract}
The hypothalamic-pituitary-adrenal (HPA) axis seems to play a major role in the development, elicitation, and enhancement of aggressive behavior in animals. Increasing evidence suggests that this is also true for humans. However, most human research on the role of the HPA axis in aggression has been focusing on highly aggressive children and adolescent clinical samples. Here, we report on a study of the role of basal and acute HPA axis activity in a sample of 20 healthy male and female adults. We used the Taylor Aggression Paradigm to induce and measure aggression. We assessed the cortisol awakening response as a trait measure of basal HPA axis activity. Salivary free cortisol measures for the cortisol awakening response were obtained on three consecutive weekdays immediately following awakening and 30, 45, and $60 \mathrm{~min}$ after. Half of the subjects were provoked with the Taylor Aggression Paradigm to behave aggressively; the other half was not provoked. Acute HPA axis activity was measured four times, once before and three times after the induction of aggression. Basal cortisol levels were significantly and negatively related to aggressive behavior in the provoked group and explained $67 \%$ of the behavioral variance. Cortisol levels following the induction of
\end{abstract}

R. Böhnke $(\bowtie) \cdot$ E. Naumann

Department of Psychology, University of Trier,

Universitätsring 15, 54286 Trier, Germany

e-mail: khan1301@uni-trier.de

K. Bertsch

Department of General Psychiatry, Heidelberg University,

Voßstr. 2, 69115 Heidelberg, Germany

M. R. Kruk

Gorlaeus Laboratory, Department of Medical Pharmacology,

LACDR, Leiden University, P.O. Box 9502.

2300 RA Leiden, The Netherlands aggression were significantly higher in the provoked group when baseline levels were taken into account. The data implicate that the HPA axis is not only relevant to the expression of aggressive behavior in clinical groups, but also to a large extent in healthy ones.

Keywords Aggression - Provocation ·

Taylor Aggression Paradigm · HPA axis .

Cortisol awakening response $\cdot$ Cortisol

\section{Introduction}

Aggressive behavior is a natural and adaptive phenomenon, but can be problematic to the society if it is exaggerated, persistent or expressed out of context (Nelson and Trainor 2007). Aggression may be defined as "any form of behavior directed toward the goal of harming or injuring another living being who is motivated to avoid such treatment" (Baron and Richardson 1994, p. 7) and is one of the most researched topics in psychology (Hennig et al. 2005). One promising system believed to be involved in aggressive behavior is the hypothalamic-pituitary-adrenal (HPA) axis and especially its end product, the glucocorticoids. The HPA axis seems to play a causal role in the formation and escalation of aggressive behavior in rodents. Both acute and basal HPA axis activity have been shown to influence aggressive behavior in rats (Kruk et al. 2004). Kruk et al. (2004) identified a positive feedback cycle, in which the activation of the HPA axis causes enhanced aggressive behavior, which in turn further activates the HPA axis. Low basal activity of the HPA axis in rats, however, is causally involved in abnormal forms of aggressive behavior (Haller et al. 2004). Several studies have confirmed the relationship of the HPA axis and aggressive behavior in humans, as well. 
A relationship between the activity of the HPA axis and aggression has become evident for example in depressed patients: those patients who have a hyperactive HPA axis are more likely to commit suicide compared to those with a normally regulated HPA axis (Coryell and Schlesser 2001). Evidence for an association between aggressive behavior and acute HPA axis activity has also come from experimental studies. In healthy adults, increases in cortisol levels following a laboratory aggression paradigm were associated with the amount of aggressive behaviors shown within that task (Gerra et al. 2001a, b, 2004, 2007). These increases were also apparent in subjects high in trait aggression (Gerra et al. 1997). These results, however, could not always be replicated (Berman et al. 1993). Thus, while there is some evidence of an acute enhancement of HPA axis activity following aggression in healthy adult males, further replication is needed.

Several studies have focused on the relationship between basal HPA axis activity and aggressive behavior. However, most of this research has centered on male children and adolescents with externalizing behavior problems. There is evidence that children with externalizing problems display lower basal cortisol levels than their respective control groups, and basal cortisol levels are negatively related to externalizing behavior (Alink et al. 2008). Age seems to be a significant moderator of this relationship, as this pattern was only observed in schoolaged children in this meta-analysis. However, children with externalizing disorders not only display enhanced aggressive behavior, but also non-aggressive disruptive behaviors (Hinshaw 1987). Other studies focusing solely on aggressive behavior and basal HPA axis activity have also reported an inverse relationship (McBurnett et al. 2000; Oosterlaan et al. 2005; Pajer et al. 2001; van de Wiel et al. 2004; van Goozen et al. 1998), though some found no relationship (van Bokhoven et al. 2005; van den Bergh et al. 2008). Interestingly, only a few studies on this topic have been conducted in adults. The available findings indicate that habitually violent offenders (Virkkunen 1985) and males with antisocial personality disorder (Bergman and Brismar 1994) have lower basal cortisol levels.

One reason for these divergent results may be methodological differences in the assessment of basal HPA axis activity. Researchers working with humans measure basal HPA axis activity mostly by taking a single measurement of cortisol levels in the morning (Pajer et al. 2001), in the afternoon (Gerra et al. 2001b), or without controlling for time of measurement (McBurnett et al. 2000). To measure trait aspects of HPA axis activity, it is generally better to measure cortisol levels in the morning since they are high (Levine et al. 2007) and more genetically influenced than afternoon or evening levels, which are mostly driven by situational factors (Schreiber et al. 2006; Wüst et al. 2000a). Increasingly, researchers use the cortisol awakening response, a surge in cortisol levels following awakening, as an index of basal HPA axis activity (Kuehner et al. 2007; Marsman et al. 2008; Wirtz et al. 2007). Hellhammer et al. (2007) suggest that to reliably estimate the trait components of HPA axis activity, the cortisol awakening response should be assessed with four measurements on at least two consecutive days. Thus, the inconsistent results regarding basal HPA axis activity and aggression may in fact be due to differing situational influences as well as differences in the time of cortisol assessment.

In summary, no clear relationship between basal HPA axis activity and aggressive behavior in humans has emerged, but there is some evidence for an acute increase in HPA axis activity in healthy males following aggression. Although it is important to understand the developmental pathways and the biological markers of aggression in clinical groups, most of the problems for society may result from escalated conflict situations involving healthy individuals (Nelson and Trainor 2007). Therefore, additional studies with healthy male and female subjects are necessary.

The aim of this study was to elucidate the relationship between basal and acute HPA axis activity and aggressive behavior in a group of healthy students. We chose a modified version of the Taylor Aggression Paradigm, also known as the competitive reaction time task, to induce and measure aggressive behavior in our subjects (Taylor 1967). This paradigm has been extensively validated (Anderson and Bushman 1997; Bernstein et al. 1987; Giancola and Zeichner 1995). We measured the cortisol awakening response on three consecutive days in a group of healthy subjects to obtain a reliable index of trait components of HPA axis activity. In an experimental session, we provoked aggressive behavior with the Taylor Aggression Paradigm and measured acute HPA axis activity. We expected a rise in cortisol levels in the provoked group and, within the provoked group, a relationship between the extent of aggressive behavior and the rise in cortisol levels. Furthermore, we predicted that basal HPA axis activity would be negatively correlated with aggressive behavior.

\section{Methods}

\section{Subjects}

Twenty students of the University of Trier, Germany (10 female and 10 male, mean age 23, SD 2.7, range 20-29) took part in the study. All subjects were right-handed. Only nonsmokers were included, since smoking is known to affect HPA axis activity (Granger et al. 2007). Furthermore, they were physically and psychologically healthy with no history of psychiatric disorders. To control for hormonal status in 
females, only those using hormonal contraceptives were included in the study. The experiment was conducted in accordance with the Declaration of Helsinki. The Research Ethics Committee of the University of Trier approved the study, and all subjects gave written informed consent. Subjects were compensated with $30 €$ (approximately US \$40).

\section{The Taylor Aggression Paradigm}

Aggression was elicited with the Taylor Aggression Paradigm. Subjects were led to believe that they were playing a competitive reaction time task against another subject of the same sex, who they met before the start of the experiment. The game consisted of 30 trials divided into 3 blocks of 10 . In each trial, subjects were instructed to react as quickly as possible to a green square by pressing a key. Subjects were informed that whoever lost a given trial would receive a blast of noise from the winner. Prior to each trial, subjects were directed to select the duration and volume of the noise to be presented to their competitor. Noise duration could be varied between $0 \mathrm{~s}$ (level 0) and $5 \mathrm{~s}$ (level 10) in $0.5 \mathrm{~s}$ increments. Volume varied between $60 \mathrm{~dB}$ (level 1) and $105 \mathrm{~dB}$ (level $10)$ in $5 \mathrm{~dB}$ increments. Level 0 on the volume scale corresponded to $0 \mathrm{~dB}$. After each trial, feedback about the outcome of the trial was presented on the screen (i.e., whether the subject won or lost). Unknown to the subjects, there was no actual 'competitor'. The outcome of the trials was held constant for all subjects (i.e., each subject won and lost half of the trials). Additionally, noise volume and duration were selected by the experimenter and varied by trial block. During the first block, all subjects received short and gentle noises when they lost a trial (volume: $M=62.5 \mathrm{~dB}$, range $0-70 \mathrm{~dB}$; duration: $M=0.75 \mathrm{~s}$, range $0-1.5 \mathrm{~s}$ ). Subjects in the non-provoked control group received the same noises during the second and third blocks. Subjects in the provoked group received noises of intermediate intensity and duration in the second block (volume: $M=82.5 \mathrm{~dB}$, range 75$90 \mathrm{~dB}$; duration: $M=2.75 \mathrm{~s}$, range $2-3.5 \mathrm{~s}$ ) and high intensity and duration in the third block (volume: $M=99 \mathrm{~dB}$, range $90-105 \mathrm{~dB}$; duration: $M=4.4 \mathrm{~s}$, range $3.5-5 \mathrm{~s})$. The duration and volume settings of the subjects were recorded in each trial on the scales from 0 to 10 . An average was computed for each subject and each trial of the volume and duration setting. Finally, the ten trials belonging to one block of the Taylor Aggression Paradigm were averaged for each subject. These values were later used as the dependent variable "aggressive behavior".

\section{Acute HPA axis activity}

During the experiment, salivary cortisol samples were collected once prior to the induction of aggression and three times after. Subjects obtained native saliva in 2-ml reaction tubes (Sarstedt, Nümbrecht, Germany). Collection tubes were positioned on the table in front of the subject and sampling instructions were given via computer. Immediately following the experiment, samples were frozen for biochemical analysis. Salivary cortisol was analyzed with a time-resolved immunoassay with fluorescence detection as described in detail elsewhere (Dressendörfer et al. 1992). Intra- and interassay variability was less than 10 and $12 \%$, respectively.

\section{Basal HPA axis activity}

To obtain a reliable trait measure of HPA axis activity, the cortisol awakening response was assessed on three consecutive weekdays prior to the experiment (Hellhammer et al. 2007). Subjects collected samples of native saliva at home each day at awakening and 30, 45, and $60 \mathrm{~min}$ later. Awakening time was arranged between 6:00 hours and 8:00 hours for all subjects since awakening time has been shown to influence the cortisol awakening response $(\mathrm{Ku}-$ dielka and Kirschbaum 2003). We tried to choose a time that fitted into the routine of each subject. In addition, time of awakening was held constant intraindividually over the 3 days. During the sampling period, subjects drank nothing but water and refrained from brushing their teeth, eating and exercising. The subjects stored all samples in the refrigerator or freezer until returning them to our laboratory on the day of the experiment. These samples were analyzed in the same manner as those obtained during the experiment (see "Acute HPA axis activity").

We chose to compute the area under the curve with respect to ground $\left(\mathrm{AUC}_{\mathrm{G}}\right)$ of the cortisol awakening response as a trait measure of HPA axis activity (Hellhammer et al. 2007). $\mathrm{AUC}_{\mathrm{G}}$ was calculated by the formula reported in Pruessner et al. (2003) and represents the entire area under the cortisol awakening response with respect to ground. The $\mathrm{AUC}_{\mathrm{G}}$ was calculated for each subject and day and then averaged over the 3 days to form one reliable indicator of basal HPA axis activity for each subject. $\mathrm{AUC}_{\mathrm{G}}$ for 19 subjects were included in the analysis, 9 in the non-provoked control and 10 in the provoked group. One subject was excluded due to lack of compliance with the sampling schedule on all 3 days. Compliance was defined as a deviation of no more than $10 \mathrm{~min}$ from the targeted time for the first and $7 \mathrm{~min}$ for the other samples (Kudielka and Kirschbaum 2003). Additionally, the $\mathrm{AUC}_{\mathrm{G}} \mathrm{S}$ of two subjects (one from each group) were averaged across only 2 days due to non-compliance on the third day. Their data were retained since the reliability of the $\mathrm{AUC}_{\mathrm{G}}$ when averaged over 2 days was still acceptable (Hellhammer et al. 2007). Exclusion of these values 
resulted in correlations of $\mathrm{AUC}_{\mathrm{G}}$ across the 3 days between 0.34 and 0.65 . This is consistent with values reported by others (Wüst et al. 2000b).

\section{Procedure}

All subjects were examined individually. We invited the subjects to a preliminary interview, in which we checked the exclusion criteria and informed them of the aim of the study and the procedure. Subjects were told that we wanted to assess the relationship between the steroid hormone cortisol, personality and the perception of and reaction to visual stimuli. The cortisol sampling and experimental procedures were also described. Eligible subjects received sampling devices and a protocol to record sampling times, as well as specific instructions concerning sleep and wakeup times on the night preceding and the morning of the sampling. Participants also received a battery of personality questionnaires to fill out at home. We further emphasized the necessity to adhere to the written instructions and sampling times.

The experiment was conducted between 13:00 hours and approximately 19:00 hours, beginning at 13:00 hours, 15:00 hours and 17:00 hours, where endogenous cortisol levels are low (Schreiber et al. 2006). The 20 subjects were randomly assigned to the provoked or non-provoked control condition, all the while keeping sex balanced across groups (5 males and females in each group). Upon arrival at the laboratory, each subject returned the questionnaires and cortisol samples and was introduced to another subject of the same sex (i.e., a confederate) with whom he or she was to play a computer game during the experiment. Subjects were then seated in a dimly lit, sound-attenuated room, $1 \mathrm{~m}$ from the computer screen. A computer keyboard and the tubes for the collection of salivary cortisol were on a table in front of them.

Each subject was fitted with an EEG-recording device (results reported elsewhere). All instructions were presented via computer. Subjects first gave a salivary cortisol sample ( $\mathrm{C} 1$, baseline measurement). Next, they completed the Taylor Aggression Paradigm, which lasted for about $10 \mathrm{~min}$. Following the aggression task, subjects gave a second cortisol sample (C2, $+15 \mathrm{~min}$ after baseline). Finally, all subjects completed a non-stressful task for approximately $20 \mathrm{~min}$ and after this gave a third cortisol sample $(\mathrm{C} 3,+35 \mathrm{~min})$ and another one about $10 \mathrm{~min}$ later (C4, $+45 \mathrm{~min}$ ). Following completion of the session, all subjects were extensively debriefed, thanked and compensated for their participation. All experimental stimuli were presented and all reactions were recorded with E-Prime $^{(}{ }^{\circ}$ experiment presentation software (Psychological Software Tools, Pittsburgh, PA). The entire laboratory session lasted approximately $90 \mathrm{~min}$.
Statistical analyses

\section{Basal HPA axis activity and aggressive behavior}

To examine the effect of the induction of aggression, repeated measures analysis of variance was conducted. Block of the Taylor Aggression Paradigm was entered as the within-subjects factor, group (i.e., provoked vs. nonprovoked) was entered as a between-subjects factor and aggressive behavior as the dependent variable. Furthermore, we included gender as a control factor, but for lack of subjects in each cell excluded interactions with other variables in the model. $\mathrm{AUC}_{\mathrm{G}}$ of the cortisol awakening response was added as a continuous factor to check for main and interaction effects concerning basal cortisol levels and aggressive behavior. Since the values of the $\mathrm{AUC}_{\mathrm{G}}$ were not skewed in the entire sample or in the two groups, the values were not $\log$ transformed prior to analysis. However, the covariate $\mathrm{AUC}_{\mathrm{G}}$ was $\mathrm{z}$-standardized (Aiken and West 1991).

\section{Acute cortisol levels and aggressive behavior}

We performed an ANOVA with the between-subject factor group, the within-subject factor time of cortisol measurement and cortisol level as the dependent variable to check whether cortisol levels increased in the provoked group due to provocation. Additionally, we controlled for gender and time of experiment $(13,15,17 \mathrm{~h})$. Since the salivary cortisol measures taken during the experiment $(\mathrm{C} 1-\mathrm{C} 4)$ were slightly skewed, they were log transformed prior to analysis. Since we found differences in our sample with respect to cortisol levels at baseline $(\mathrm{C} 1)$ in the analysis of variance, we conducted an additional univariate analysis of covariance with the factor group and cortisol levels after the induction of aggression procedure $(\mathrm{C} 3,20 \mathrm{~min}$ after induction of aggression) as the dependent variable with cortisol levels at baseline included as a covariate. Additionally, we correlated aggressive behavior with the change in cortisol levels from before to after the Taylor Aggression Paradigm in the provoked group to analyze whether the amount of aggression in this group was related to an increase in cortisol levels. Since it takes about 20-30 min after a stressor for cortisol levels to reach their peak in saliva (Kirschbaum and Hellhammer 1989), the difference between sample C3 (20 min after the induction of aggression) and the baseline sample $\mathrm{C} 1$ was calculated. Note that for better interpretation, Fig. 3 shows original non-transformed cortisol values as the mean \pm standard error of the mean (SEM).

For the ANOVAs, the degrees of freedom were HuynhFeldt corrected if the assumption of sphericity was violated and only adjusted results are reported (Huynh and Feldt 
1976). We calculated Hays' $\omega^{2}$ as an effect size measure (Hays 1974). An effect of $1 \%$ is considered small, $5 \%$ is considered medium and $14 \%$ is considered a large effect (Cohen 1988). In case of significant effects, we used Dunn's multiple comparison procedure as well as Pearson's correlations as post hoc tests. Statistical analyses were conducted with SPSS for Windows (Version 14.0, SPSS Inc.). The statistical significance level was set to $\alpha=0.05$.

\section{Results}

\section{Subjects' characteristics}

Table 1 shows a comparison of subjects from the provoked and non-provoked control group. Subjects assigned to either condition of the Taylor Aggression Paradigm did not differ in demographic variables, time of experiment, wakeup time, sleep duration, cortisol increase from 0 to $30 \mathrm{~min}$ post-awakening and area under the curve $\mathrm{AUC}_{\mathrm{G}}$ of the cortisol awakening response.

Manipulation check: aggressive behavior in the Taylor Aggression Paradigm

The means and standard errors for each group and block are presented in Fig. 1. The provoked group displayed generally more aggressive behavior $(M=3.39$, SEM $=$ $0.30)$ than the non-provoked control group $(M=2.30$, SEM $=0.31$ ). This was especially the case for the second and third block of the Taylor Aggression Paradigm. The main effects of group $(F(1,14)=6.37, \quad P=0.024$, $\left.\omega^{2}=0.22\right)$ and of block of the Taylor Aggression Para$\operatorname{digm}\left(F(2,28)=13.43, \quad P=0.000, \omega^{2}=0.30\right)$ were significant and large, as was the interaction group $\times$ block of the Taylor Aggression Paradigm $(F(2,28)=8.40$, $P=0.003, \omega^{2}=0.21$ ). Post hoc tests showed that the provoked group was significantly more aggressive than the non-provoked control group in blocks 2 and 3. Furthermore, within the provoked group, all blocks were significantly different from one another, with subjects being least aggressive in block 1 and most aggressive in block 3. The non-provoked control group showed low levels of aggression throughout the experiment.

Basal cortisol levels and aggressive behavior

The cortisol awakening response was robust on all 3 days. Cortisol levels increased on average $75 \%$ from awakening to $30 \mathrm{~min}$ after, which is above average (Wüst et al. 2000b).

The area under the curve of the cortisol awakening response could explain a majority of the variance of

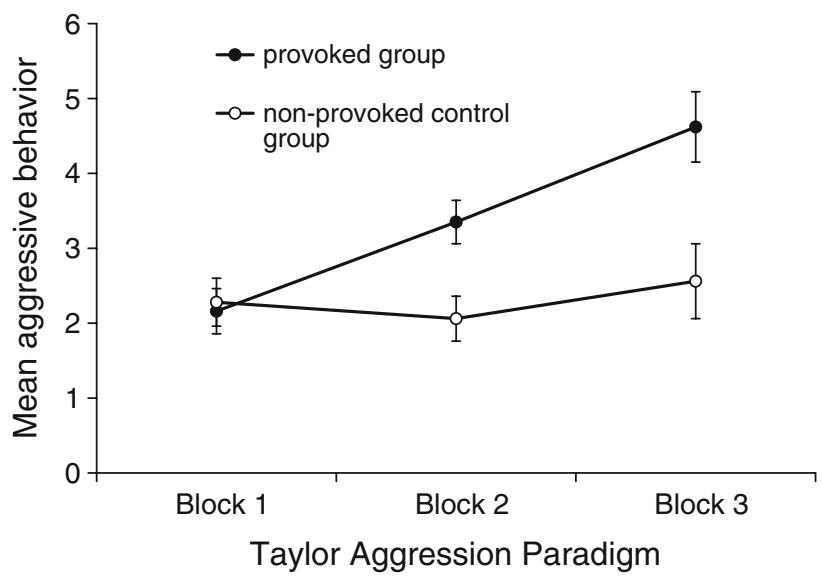

Fig. 1 Aggressive behavior over the three blocks of the Taylor Aggression Paradigm in the provoked group and the non-provoked control group. Values are means \pm SEM

Table 1 Characteristics of the subjects in the provoked group and non-provoked control group $(n=20)$

\begin{tabular}{|c|c|c|c|c|}
\hline & $\begin{array}{l}\text { Provoked } \\
M(\%)(\mathrm{SD})\end{array}$ & $\begin{array}{l}\text { Non-provoked } \\
M(\%)(\mathrm{SD})\end{array}$ & Statistical test value & $P$ value \\
\hline Age (years) & $23.50(2.87)$ & $22.60(2.50)$ & $t(18)=0.75$ & 0.465 \\
\hline$\%$ Women & 50 & 50 & $\chi^{2}(18)=0.00$ & 1.00 \\
\hline Time of experiment $(\mathrm{h})$ & $14: 12(01: 24)$ & $15: 24(01: 35)$ & $t(18)=-1.80$ & 0.089 \\
\hline Wake-up time $(\mathrm{h})^{\mathrm{a}}$ & 07:04 (00:38) & 07:02 (00:33) & $t(17)=0.12$ & 0.905 \\
\hline Sleep duration $(\mathrm{h})^{\mathrm{a}}$ & $06: 26(00: 55)$ & 06:36 (01:08) & $t(17)=-0.37$ & 0.716 \\
\hline Mean increase $(\mathrm{nmol} / \mathrm{l})^{\mathrm{a}, \mathrm{b}}$ & $5.90(2.92)$ & $6.19(3.71)$ & $t(17)=-0.19$ & 0.853 \\
\hline $\mathrm{AUC}_{\mathrm{G}}(\mathrm{nmol} / \mathrm{l})^{\mathrm{a}, \mathrm{c}}$ & $777.96(126.81)$ & $752.91(179.38)$ & $t(17)=0.32$ & 0.754 \\
\hline
\end{tabular}


aggressive behavior seen in the provoked group. Although there was no main effect of $\mathrm{AUC}_{\mathrm{G}}(F(1,14)=1.04$, $P=0.325)$, it interacted significantly with group $\left(F(1,14)=14.64, P=0.002, \omega^{2}=0.42\right)$. Post hoc Pearson correlations revealed a significant negative relationship between $\mathrm{AUC}_{\mathrm{G}}$ and aggressive behavior in the provoked group ( $r=-0.82, P=0.003$ ), displayed in Fig. 2 . In the non-provoked control group, this correlation was positive, but not significant ( $r=0.53, P=0.144)$. No other main or interaction effects with $\mathrm{AUC}_{\mathrm{G}}$ were found (all $F$ 's $<2.72$, all $P$ 's $>0.098)$. The same results were obtained, when $\mathrm{AUC}_{\mathrm{G}}$ was $\log$ transformed prior to analysis.

Acute cortisol levels and aggressive behavior

Cortisol levels only increased slightly in the provoked group. The means and standard errors of the cortisol measurements in both groups are presented in Fig. 3. There was a significant interaction effect of time of cortisol measurement and group $(F(3,45)=4.67, \quad P=0.012$, $\omega^{2}=0.12$ ). However, post hoc tests indicated that the non-provoked control group had higher cortisol levels at baseline and time point $\mathrm{C} 2$ than the provoked group. Furthermore, within the non-provoked control group, cortisol levels decreased significantly over time from baseline to samples C3 and C4. The increase in the provoked group was not significant. The univariate analysis of covariance comparing the two groups at time point $\mathrm{C} 3$, while controlling for baseline levels was, however, highly significant $\left(F(1,16)=10.05, \quad P=0.006, \omega^{2}=0.32\right)$, with higher cortisol levels in the provoked group. Neither the main effect of group $(F(1,16)<1)$ nor the main effect of time of

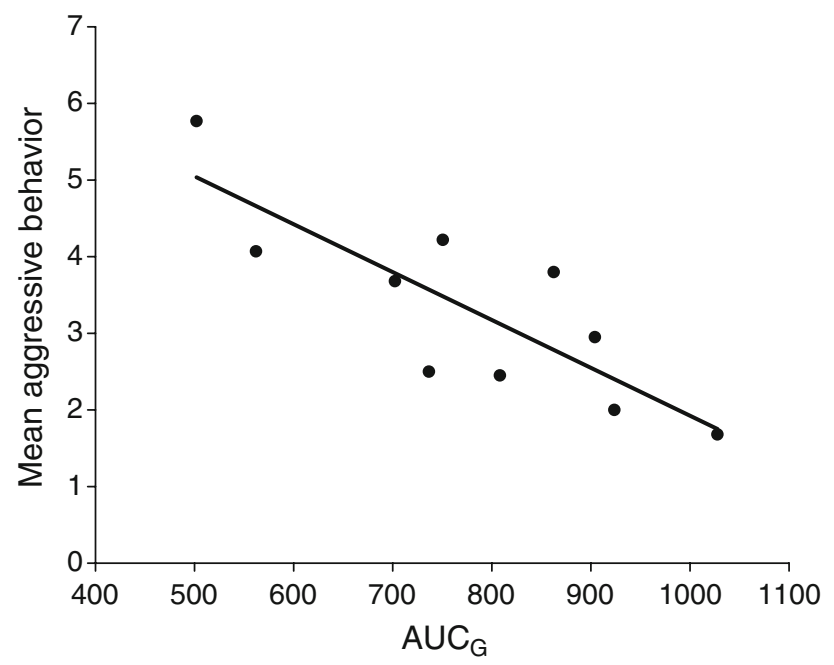

Fig. 2 Correlation of the area under the curve $\mathrm{AUC}_{\mathrm{G}}$ of the cortisol awakening response and mean aggressive behavior in the provoked group $(n=10) . R^{2}=0.67$ cortisol measurement $(F(3,45)=1.91, P=0.159)$ were significant. Furthermore, the difference in cortisol levels in the provoked group from before $(\mathrm{C} 1)$ to after the Taylor Aggression Paradigm (C3) was not related to the amount of aggressive behavior: neither aggressive behavior averaged over all blocks ( $r=0.04, P=0.911)$ nor in any one block $(-0.06<$ all $r<0.31$, all $P>0.385)$.

\section{Discussion}

The purpose of the present study was to analyze the relationship between aggressive behavior and basal as well as acute HPA axis activity. We experimentally induced aggressive behavior with the Taylor Aggression Paradigm and related the displayed aggressive behavior to basal and acute HPA axis activity levels in healthy subjects. Overall, subjects in the provoked group exhibited more aggressive behavior than the non-provoked controls. There was a significant decrease in cortisol levels in the non-provoked subjects that was absent in the provoked group, leading to significantly higher cortisol levels in the provoked group after the induction of aggression, when baseline cortisol levels were controlled for. Additionally, basal HPA axis activity accounted for a large portion of the variance in aggressive behavior within the provoked group. In the following section, we will first review the data from the Taylor Aggression Paradigm. We will then discuss

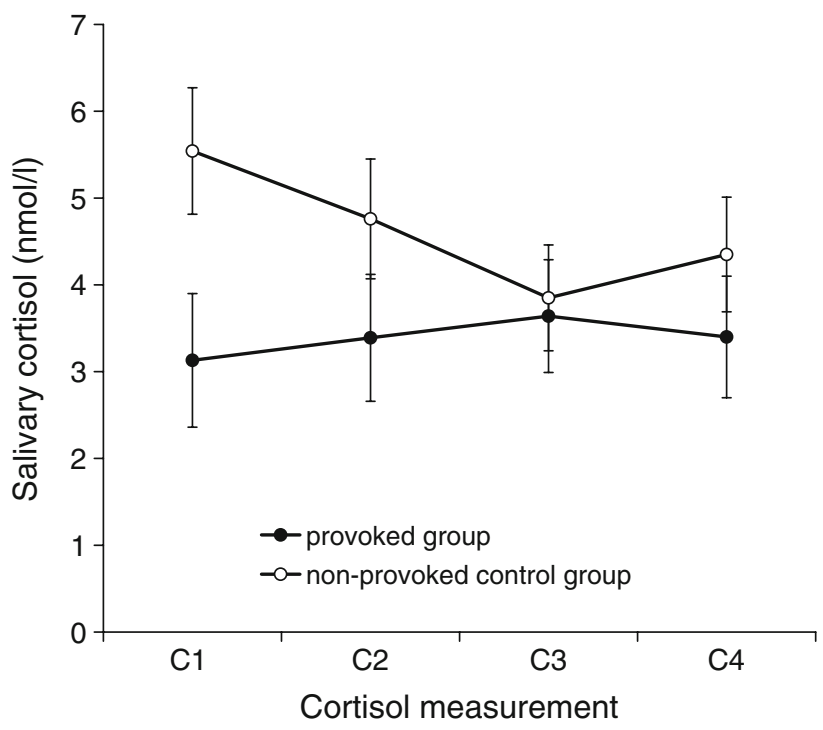

Fig. 3 Cortisol levels during the experiment in the provoked group and the non-provoked control group. $\mathrm{C} 1$, baseline before induction of aggression; C2, shortly after induction of aggression; C3, about 20 min after induction of aggression; $\mathrm{C} 4$, at the end of the experiment, about $30 \mathrm{~min}$ after induction of aggression. Values are original means \pm SEM 
the results with respect to the acute levels of HPA axis activity and aggressive behavior, after which we will address the results of basal HPA axis activity and aggressive behavior.

Results indicate that the induction of aggression with the Taylor Aggression Paradigm was successful. Subjects in the provoked group reacted more aggressively during blocks 2 and 3 than those in the non-provoked control group. Aggressive behavior also significantly increased over the three blocks in the provoked group. The interaction of group and block of the Taylor Aggression Paradigm accounted for $21 \%$ of the behavioral variance.

The interaction of group and time of cortisol measurement was significant, but this effect was due to differences in baseline cortisol levels and changes within the nonprovoked control group. Specifically, cortisol levels in the non-provoked control group were higher at the beginning and decreased significantly over the course of the experiment, whereas cortisol levels in the provoked group remained stable for the entire time. Since participants were randomly assigned to the two groups, the small number of participants may have contributed to this effect. When controlling for these baseline differences in cortisol levels between groups, there was a significant and large difference in cortisol levels after the induction of aggression, with higher levels in the provoked group. Whereas the decrease observed in the non-provoked control group may represent the normal afternoon decline in cortisol levels, the absence of a decrease in cortisol levels in the provoked group may indicate enhanced activity of the HPA axis (Reuter 2002). However, in contrast to other studies (Gerra et al. 2007), we did not find a correlation between aggressive behavior and the amount of cortisol increase. A reason for these discrepant results could be our choice of the Taylor Aggression Paradigm to induce aggression. The Taylor Aggression Paradigm was shorter in duration than the task used by Gerra et al. and might as such have been less stressful. This is supported by another study that used the Taylor Aggression Paradigm and assessed acute HPA axis activity (Berman et al. 1993), which also found no increase in cortisol levels in the provoked group.

Basal HPA axis activity was significantly and negatively related to aggressive behavior in the provoked group and accounted for as much as $67 \%$ of the variance in aggressive behavior across all blocks. Subjects with lower levels of basal HPA axis activity chose higher and longer noise settings for their opponents on being provoked. As demonstrated in a study with animals, chronically low basal glucocorticoid levels have been linked to extreme forms of aggression. For example, Halasz et al. (2002) showed that glucocorticoid deficiency was associated with changes in neural functioning, including a heightened activation of the central amygdala. This might lead to social deficits, where ambiguous or neutral situations are misinterpreted and thus lead to a lower threshold for aggressive behavior. Indeed, changes in social information processing, especially of ambiguous social stimuli, have been documented in highly aggressive children (Milich and Dodge 1984). We speculate that in our healthy subjects the same mechanisms might be involved, only in a less severe manner. Subjects with low basal HPA axis activity may be more sensitive to situational provocation and react more aggressively than subjects with higher basal HPA axis activity. In contrast, this negative relationship between aggressive behavior and basal HPA axis activity was not present in the nonprovoked control group, where the correlation was positive, albeit non-significant. Qualitative differences between aggressive behavior in the two groups may explain these different associations with basal HPA axis activity, since aggressive behavior in the provoked group was more of a reactive kind compared to that in the non-provoked group, which was also generally lower (Bettencourt et al. 2006). Several studies have noted different underlying biological mechanisms for these aggression subtypes (Nelson and Trainor 2007; Strüber et al. 2008). This has also been recently shown for the HPA axis (Lopez-Duran et al. 2009), in that HPA axis reactivity to stressful situations in children was positively related to reactive, but not to proactive aggression. By extension, it seems likely that low basal HPA axis activity may lead to heightened reactive aggression in situations involving provocation, but may impede the elicitation of (proactive) aggression in non- or only low provoking situations. However, the positive correlation for proactive aggression displayed by the nonprovoked control group needs to be validated with a larger sample.

When interpreting the results of the present study, several limitations have to be kept in mind. First, we chose to analyze a relatively small number of subjects. However, even with this small sample, a significant and large effect of basal HPA axis activity and aggression was observed in the provoked group. Second, we could not analyze the interaction effects of sex with other independent variables since the amount of subjects in each cell was too low. But, we controlled for sex effects by having an equal amount of men and women in each group and by including this factor as a covariate into the analysis. Third, as discussed above, the provocation we used was relatively mild compared to other experimental settings, which have previously been used to activate the HPA axis, or real world conflict situations. While this may explain our lack of findings for an increase in cortisol, we did find a significant difference between the two groups, in that the provoked group had higher levels than the non-provoked control group when controlling for baseline levels. Furthermore, the significant differences observed in aggressive behavior between the 
provoked and non-provoked control group suggest that the task was effective.

This is the first time that the relationship between the trait components of HPA axis activity and aggressive behavior was analyzed experimentally in a group of healthy subjects. When trait aspects of basal HPA axis activity are reliably assessed, large effects on aggressive behavior within healthy adults can be observed in provoking situations. The study further underlines the importance of distinguishing between basal and acute HPA axis activity, since both relate to aggressive behavior in different ways, and of measuring them accordingly.

Acknowledgments This research was supported by the International Research Training Group "The Psychoneuroendocrinology of Stress" of the Deutsche Forschungsgemeinschaft (DFG, GRK1389/1, Project H). The authors wish to thank John J. Sollers III and LaBarron Hill from The Ohio State University for language editing of the manuscript.

Open Access This article is distributed under the terms of the Creative Commons Attribution Noncommercial License which permits any noncommercial use, distribution, and reproduction in any medium, provided the original author(s) and source are credited.

\section{References}

Aiken LS, West SG (1991) Multiple regression: testing and interpreting interactions. Sage, Newbury

Alink LR, van Ijzendoorn MH, Bakermans-Kranenburg MJ, Mesman J, Juffer F, Koot HM (2008) Cortisol and externalizing behavior in children and adolescents: mixed meta-analytic evidence for the inverse relation of basal cortisol and cortisol reactivity with externalizing behavior. Dev Psychobiol 50:427-450

Anderson CA, Bushman BJ (1997) External validity of "trivial" experiments: the case of laboratory aggression. Rev Gen Psychol $1: 19-41$

Baron RA, Richardson DR (1994) Human aggression. Plenum Press, New York

Bergman B, Brismar B (1994) Hormone levels and personality traits in abusive and suicidal male alcoholics. Alcohol Clin Exp Res 18:311-316

Berman M, Gladue B, Taylor S (1993) The effects of hormones, Type A behavior pattern, and provocation on aggression in men. Motiv Emot 17:125-138

Bernstein S, Richardson D, Hammock G (1987) Convergent and discriminant validity of the Taylor and Buss measures of physical aggression. Aggress Behav 13:15-24

Bettencourt BA, Talley A, Benjamin AJ, Valentine J (2006) Personality and aggressive behavior under provoking and neutral conditions: a meta-analytic review. Psychol Bull 132:751-777

Cohen J (1988) Statistical power analysis for the behavioral sciences. Erlbaum, Hillsdale

Coryell W, Schlesser M (2001) The dexamethasone suppression test and suicide prediction. Am J Psychiatry 158:748-753

Dressendörfer RA, Kirschbaum C, Rohde W, Stahl F, Strasburger CJ (1992) Synthesis of a cortisol-biotin conjugate and evaluation as a tracer in an immunoassay for salivary cortisol measurement. J Steroid Biochem Mol Biol 43:683-692
Gerra G, Zaimovic A, Ampollini R, Giusti F, Delsignore R, Raggi MA, Laviola G, Macchia T, Brambilla F (2001a) Experimentally induced aggressive behavior in subjects with 3, 4-methylenedioxy-methamphetamine ("Ecstasy") use history: psychobiological correlates. J Subst Abuse 13:471-491

Gerra G, Zaimovic A, Avanzini P, Chittolini B, Giucastro G, Caccavari R, Palladino M, Maestri D, Monica C, Delsignore R, Brambilla F (1997) Neurotransmitter-neuroendocrine responses to experimentally induced aggression in humans: influence of personality variable. Psychiatry Res 66:33-43

Gerra G, Zaimovic A, Moi G, Bussandri M, Bubici C, Mossini M, Raggi MA, Brambilla F (2004) Aggressive responding in abstinent heroin addicts: neuroendocrine and personality correlates. Prog Neuropsychopharmacol Biol Psychiatry 28:129-139

Gerra G, Zaimovic A, Raggi MA, Giusti F, Delsignore R, Bertacca S, Brambilla F (2001b) Aggressive responding of male heroin addicts under methadone treatment: psychometric and neuroendocrine correlates. Drug Alcohol Depend 65:85-95

Gerra G, Zaimovic A, Raggi MA, Moi G, Branchi B, Moroni M, Brambilla F (2007) Experimentally induced aggressiveness in heroin-dependent patients treated with buprenorphine: comparison of patients receiving methadone and healthy subjects. Psychiatry Res 149:201-213

Giancola PR, Zeichner A (1995) Construct validity of a competitive reaction-time aggression paradigm. Aggress Behav 21:199-204

Granger DA, Blair C, Willoughby M, Kivlighan KT, Hibel LC, Fortunato CK, Wiegand LE (2007) Individual differences in salivary cortisol and alpha-amylase in mothers and their infants: relation to tobacco smoke exposure. Dev Psychobiol 49:692-701

Halasz J, Liposits Z, Kruk MR, Haller J (2002) Neural background of glucocorticoid dysfunction-induced abnormal aggression in rats: involvement of fear- and stress-related structures. Eur J Neurosci 15:561-569

Haller J, Halasz J, Mikics E, Kruk MR (2004) Chronic glucocorticoid deficiency-induced abnormal aggression, autonomic hypoarousal, and social deficit in rats. J Neuroendocrinol 16:550-557

Hays WL (1974) Statistics. Holt, Rinehart \& Winston, London

Hellhammer J, Fries E, Schweisthal OW, Schlotz W, Stone AA, Hagemann D (2007) Several daily measurements are necessary to reliably assess the cortisol rise after awakening: state- and trait components. Psychoneuroendocrinology 32:80-86

Hennig J, Reuter M, Netter P, Burk C, Landt O (2005) Two types of aggression are differentially related to serotonergic activity and the A779C TPH polymorphism. Behav Neurosci 119:16-25

Hinshaw SP (1987) On the distinction between attentional deficits/ hyperactivity and conduct problems/aggression in child psychopathology. Psychol Bull 101:443-463

Huynh H, Feldt LS (1976) Estimation of the box correction for degrees of freedom from sample data in randomized block and splitsplot designs. J Educ Stat 1:69-82

Kirschbaum C, Hellhammer DH (1989) Salivary cortisol in psychobiological research: an overview. Neuropsychobiology 22:150 169

Kruk MR, Halasz J, Meelis W, Haller J (2004) Fast positive feedback between the adrenocortical stress response and a brain mechanism involved in aggressive behavior. Behav Neurosci 118:1062-1070

Kudielka BM, Kirschbaum C (2003) Awakening cortisol responses are influenced by health status and awakening time but not by menstrual cycle phase. Psychoneuroendocrinology 28:35-47

Kuehner C, Holzhauer S, Huffziger S (2007) Decreased cortisol response to awakening is associated with cognitive vulnerability to depression in a nonclinical sample of young adults. Psychoneuroendocrinology 32:199-209 
Levine A, Zagoory-Sharon O, Feldman R, Lewis JG, Weller A (2007) Measuring cortisol in human psychobiological studies. Physiol Behav 90:43-53

Lopez-Duran NL, Olson SL, Hajal NJ, Felt BT, Vazquez DM (2009) Hypothalamic pituitary adrenal axis functioning in reactive and proactive aggression in children. J Abnorm Child Psychol 37:169-182

Marsman R, Swinkels SH, Rosmalen JG, Oldehinkel AJ, Ormel J, Buitelaar JK (2008) HPA-axis activity and externalizing behavior problems in early adolescents from the general population: the role of comorbidity and gender The TRAILS study. Psychoneuroendocrinology 33:789-798

McBurnett K, Lahey BB, Rathouz PJ, Loeber R (2000) Low salivary cortisol and persistent aggression in boys referred for disruptive behavior. Arch Gen Psychiatry 57:38-43

Milich R, Dodge KA (1984) Social information processing in child psychiatric populations. J Abnorm Child Psychol 12:471-489

Nelson RJ, Trainor BC (2007) Neural mechanisms of aggression. Nat Rev Neurosci 8:536-546

Oosterlaan J, Geurts HM, Knol DL, Sergeant JA (2005) Low basal salivary cortisol is associated with teacher-reported symptoms of conduct disorder. Psychiatry Res 134:1-10

Pajer K, Gardner W, Rubin RT, Perel J, Neal S (2001) Decreased cortisol levels in adolescent girls with conduct disorder. Arch Gen Psychiatry 58:297-302

Pruessner JC, Kirschbaum C, Meinlschmid G, Hellhammer DH (2003) Two formulas for computation of the area under the curve represent measures of total hormone concentration versus timedependent change. Psychoneuroendocrinology 28:916-931

Reuter M (2002) Impact of cortisol on emotions under stress and nonstress conditions: a pharmacopsychological approach. Neuropsychobiology 46:41-48

Schreiber JE, Shirtcliff E, Van Hulle C, Lemery-Chalfant K, Klein MH, Kalin NH, Essex MJ, Goldsmith HH (2006) Environmental influences on family similarity in afternoon cortisol levels: twin and parent-offspring designs. Psychoneuroendocrinology 31:1131-1137
Strüber D, Lück M, Roth G (2008) Sex, aggression and impulse control: an integrative account. Neurocase 14:93-121

Taylor SP (1967) Aggressive behavior and physiological arousal as a function of provocation and the tendency to inhibit aggression. J Pers 35:297-310

van Bokhoven I, Van Goozen SH, van Engeland H, Schaal B, Arseneault L, Seguin JR, Nagin DS, Vitaro F, Tremblay RE (2005) Salivary cortisol and aggression in a population-based longitudinal study of adolescent males. J Neural Transm 112:1083-1096

van de Wiel NM, van Goozen SH, Matthys W, Snoek H, van Engeland H (2004) Cortisol and treatment effect in children with disruptive behavior disorders: a preliminary study. J Am Acad Child Adolesc Psychiatry 43:1011-1018

van den Bergh BR, van Calster B, Pinna Puissant S, van Huffel S (2008) Self-reported symptoms of depressed mood, trait anxiety and aggressive behavior in post-pubertal adolescents: associations with diurnal cortisol profiles. Horm Behav 54:253-257

van Goozen SH, Matthys W, Cohen-Kettenis PT, Gispen-de Wied C, Wiegant VM, van Engeland H (1998) Salivary cortisol and cardiovascular activity during stress in oppositional-defiant disorder boys and normal controls. Biol Psychiatry 43:531-539

Virkkunen M (1985) Urinary free cortisol secretion in habitually violent offenders. Acta Psychiatr Scand 72:40-44

Wirtz PH, von Kanel R, Emini L, Ruedisueli K, Groessbauer S, Maercker A, Ehlert U (2007) Evidence for altered hypothalamus-pituitary-adrenal axis functioning in systemic hypertension: blunted cortisol response to awakening and lower negative feedback sensitivity. Psychoneuroendocrinology 32:430-436

Wüst S, Federenko I, Hellhammer DH, Kirschbaum C (2000a) Genetic factors, perceived chronic stress, and the free cortisol response to awakening. Psychoneuroendocrinology 25:707-720

Wüst S, Wolf J, Hellhammer DH, Federenko I, Schommer N, Kirschbaum C (2000b) The cortisol awakening responsenormal values and confounds. Noise Health 2:79-88 